\title{
Obesity management in Prader-Willi syndrome: current perspectives
}

This article was published in the following Dove Press journal: Diabetes, Metabolic Syndrome and Obesity:Targets and Therapy

\section{Antonino Crinò' \\ Danilo Fintini² \\ Sarah Bocchini' \\ Graziano Grugni ${ }^{3}$}

'Autoimmune Endocrine Diseases Unit, ${ }^{2}$ Endocrinology Unit, Bambino Gesù Children's Hospital, Research Institute, Palidoro, Rome; ${ }^{3}$ Division of Auxology, Italian Auxological Institute, Research Institute, Piancavallo, Verbania, Italy
Correspondence: Antonino Crinò Autoimmune Endocrine Diseases Unit, Bambino Gesù Children's Hospital, Research Institute, Via Torre di Palidoro, Palidoro, Rome 00050, Italy

Tel +390668593418

Fax +3906 68593207

Email antonino.crino@opbg.net
Abstract: Prader-Willi syndrome (PWS) is a complex multisystem disorder due to the absent expression of the paternally active genes in the PWS critical region on chromosome 15 (15q11.2q13). The syndrome is considered the most common genetic cause of obesity, occurring in 1:10,000-1:30,000 live births. Its main characteristics include neonatal hypotonia, poor feeding, and lack of appetite in infancy, followed by weight gain, lack of satiety, and uncontrolled appetite, frequently after the age of 2-3 years. The clinical picture includes short stature, multiple endocrine abnormalities (hypogonadism, growth hormone/insulin-like growth factor-I axis dysfunction, hypothyroidism, central adrenal insufficiency), dysmorphic features, scoliosis, osteoporosis, mental retardation, and behavioral and psychiatric problems. Subjects with PWS will become severely obese unless their food intake is strictly controlled. Constant and obsessive food seeking behavior can make life very difficult for both the family and caretakers. Prevention of obesity is mandatory in these patients from the first years of life, because once obesity develops it is difficult to maintain the control of food intake. In fact, PWS subjects die prematurely from complications conventionally related to obesity, including diabetes mellitus, metabolic syndrome, sleep apnea, respiratory insufficiency, and cardiovascular disease. The mechanisms underlying hyperphagia in PWS are not completely known, and to date no drugs have proven their efficacy in controlling appetite. Consequently, dietary restriction, physical activity, and behavior management are fundamental in the prevention and management of obesity in PWS. In spite of all available therapeutic tools, however, successful weight loss and maintenance are hardly accomplished. In this context, clinical trials with new drugs have been initiated in order to find new possibilities of a therapy for obesity in these patients. The preliminary results of these studies seem to be encouraging. On the other hand, until well-proven medical treatments are available, bariatric surgery can be taken into consideration, especially in PWS patients with life-threatening comorbidities.

Keywords: Prader-Willi syndrome, severe obesity, hyperphagia, genetic obesity, food management

\section{Introduction}

Prader-Willi syndrome (PWS) is considered the most frequent genetic cause of obesity, occurring in $\sim 1: 10,000-1: 30,000$ live births. ${ }^{1,2}$ PWS arises due to the loss of expression of paternally derived genes in the PWS critical region on chromosome $15 q 11-q 13$. About $65 \%-70 \%$ of the cases are due to the deletion of this region (type 1 or 2 , depending on the proximal break point), $20 \%-30 \%$ are caused by a maternal uniparental disomy (UPD) of chromosome 15 , and most of the remaining $2 \%-5 \%$ have an imprinting center defect or unbalanced translocations $(\sim 1 \%){ }^{3}$ More recently, 
a significant change in the distribution of molecular mechanisms over time has been observed, with a larger proportion of UPD. ${ }^{4}$

PWS is a complex multisystem disorder, characterized by neonatal hypotonia and feeding difficulties in early infancy, short stature, behavioral problems, cognitive impairment, psychiatric illness, dysmorphic features (characteristic facial appearance, small hands and feet, narrow hands with straight ulnar border, scoliosis), multiple endocrine abnormalities (hypogonadism, growth hormone [GH]/insulin-like growth factor-I axis dysfunction, hypothyroidism, central adrenal insufficiency), early development of hyperphagia with food seeking behavior, and progressive development of severe obesity, unless eating is not promptly restricted., ${ }^{5,6} \mathrm{~A}$ complex hypothalamic dysregulation is currently thought to be responsible for the PWS phenotype.

It is noteworthy to see that the course of the syndrome differs significantly during the life span. ${ }^{1,5}$ Classically, the typical clinical picture becomes more evident in adulthood. However, early diagnosis combined with multidisciplinary care can change the natural history of PWS favorably. ${ }^{7}$

Consequently, the diagnosis of PWS should be confirmed very early during the neonatal period, thanks to the development of genetic testing. In this context, findings that should prompt diagnostic testing have been established. ${ }^{8}$ All three of the main genetic abnormalities (deletion, UPD15, and imprinting center defect) can be detected by methylationspecific multiplex ligation-dependent probe amplification analysis. Nevertheless, a high-resolution karyotype is necessary in order to recognize the cases with translocations or other rare chromosomal rearrangements which involve chromosome $15 .^{1,9}$

The mortality rate is higher in patients with PWS than within the general population, and prognosis is significantly conditioned by proactive interventions to prevent morbid weight excess. ${ }^{10}$ For this reason, in this review we analyze the therapeutic options available for the treatment of obesity in PWS, including pharmacological and surgical strategies.

\section{Obesity in PWS}

The frequency of obesity in the PWS population varies according to the different age groups, although in all cases it reaches a significant percentage. A prevalence of overweight and obesity of $40 \%$ have been reported in children and adolescents. ${ }^{11}$ When considering adulthood, the sum of obese and overweight subjects reaches a percentage ranging from $82 \%$ to $98 \%$, depending on the different study groups. ${ }^{12,13}$
Individuals with PWS characteristically have poor feeding and lack of appetite in infancy, followed by uncontrolled appetite and lack of satiety that lead to weight gain, mostly after the age of 2-3 years. These subjects are frequently unable to sense when they are full after eating.

In the absence of rigorous supervision of food intake, many PWS patients weigh more than twice their ideal body weight.

The growing understanding of the natural history of PWS has more recently identified seven successive nutritional and eating behavior phases, proceeding from poor feeding and failure to thrive (Phase 1a), to normal eating without (Phase 1b) or with obesity (Phase $2 \mathrm{a}$ ), to increased interest for food and weight gain (Phase 2b), and to hyperphagia and life-threatening obesity (Phase 3 ). ${ }^{14}$

In the later stages, PWS results in constant and inexorable hunger that drives patients to engage in problematic hungerrelated behaviors with affected individuals who do not feel satisfied after completing a meal.

It is noteworthy to observe that in these patients obesity may begin even before the child exhibits a substantial increase in food intake or interest.

In these subjects, excessive eating behavior may have some variations in its nature and severity, but it is clearly a significant, salient, and constant feature of the syndrome, observed in all genetic subtypes. Patients with PWS typically display aggressive and obsessive food seeking, food storage, foraging, and hoarding and stealing of either food or money to buy food, which are viewed by some physicians as part of a broader abnormal behavior. All of these represent a lifelong source of distress for patients and families and negatively affect social adaptation, occupational performance, and quality of life. PWS individuals are forced to live a dependent life, requiring strict control over access to food and continuous care and supervision. Otherwise, most individuals with PWS will go to great lengths to eat large quantities of food, even if it is spoiled, indigestible, or unpalatable to others. It is of note, however, that some adults may develop satiety and reduce their search for food during adulthood (Phase 4). ${ }^{5-14}$

Obesity of PWS subjects shows distinct phenotypic and metabolic characteristics that are not common to simple obesity. ${ }^{1}$ In fact, lean body mass is lower in PWS subjects than in normal weight individuals and even more so than in obese subjects. Decreased muscle mass is responsible for reduced resting energy expenditure (REE), but a normal relationship between fat-free mass and REE is maintained in PWS subjects. ${ }^{15}$ Individuals with PWS harbor a higher fat mass than simple obesity, under the same degree of body mass index (BMI), both in children and in adults. Excessive fat mass in 
PWS typically affects the trunk and the proximal extremity of the limbs. Differently to what occurs in non-syndromic obesity, PWS subjects showed lower trunk-to-appendicular fat mass ratio and lower visceral adiposity. In line with these findings, a higher insulin sensitivity is generally reported in PWS patients when compared to a matched obese population. ${ }^{16}$ Data about insulin secretion and body composition in PWS, however, are not univocal. Other authors have observed that PWS and obese controls had similar insulin levels and were similarly insulin resistant. ${ }^{17}$ In addition, PWS subjects with severe obesity have been reported to have a similar proportion of abdominal subcutaneous and visceral fat in comparison to BMI-matched controls. ${ }^{18}$ More recently, a lower proportion of trunkal fat was found in obese women with PWS than in those with essential obesity. ${ }^{19}$

Altered brain structures have been documented in PWS that may underlie the excessive hyperphagia and the constant hunger, including low number of oxytocin neurones in the hypothalamus ${ }^{20}$ and reduced fractional anisotropy of white matter fibers. ${ }^{21}$ More recently, it has been shown that selective disruption of Snord116 expression in the mediobasal hypothalamus models the hyperphagia of PWS. ${ }^{22}$ However, body weight gain in mice lacking Snord116 is limited to the first 18 weeks of life. Mice carrying a deletion of the Magel2 gene (Magel2KO) is another experimental model of PWS characterized by overeating. New evidence suggests that intraperitoneal administration of oleoylethanolamide (a lipid messenger, produced by small-intestinal enterocytes, that controls feeding, body weight, and energy metabolism) in Magel2KO mice is able to reduce food intake, probably acting through mechanisms underlying satiety control. ${ }^{23}$ These results, combined with imaging studies showing both an increased functional response of the hypothalamus to food stimuli, ${ }^{24}$ the involvement of the amygdala, ${ }^{25}$ and the reduced coupling of the ventral striatum with limbic structures for basic internal homeostasis, ${ }^{26}$ suggest a crucial role of several brain areas in the abnormal regulation of food intake in PWS.

\section{Endocrine control of eating behavior in PWS}

Several clinical studies have been carried out to evaluate the appetite regulatory systems in PWS patients, in order to understand the role of endogenous appetite suppressants and stimulants underlying the hyperphagic attitude (Figure 1).

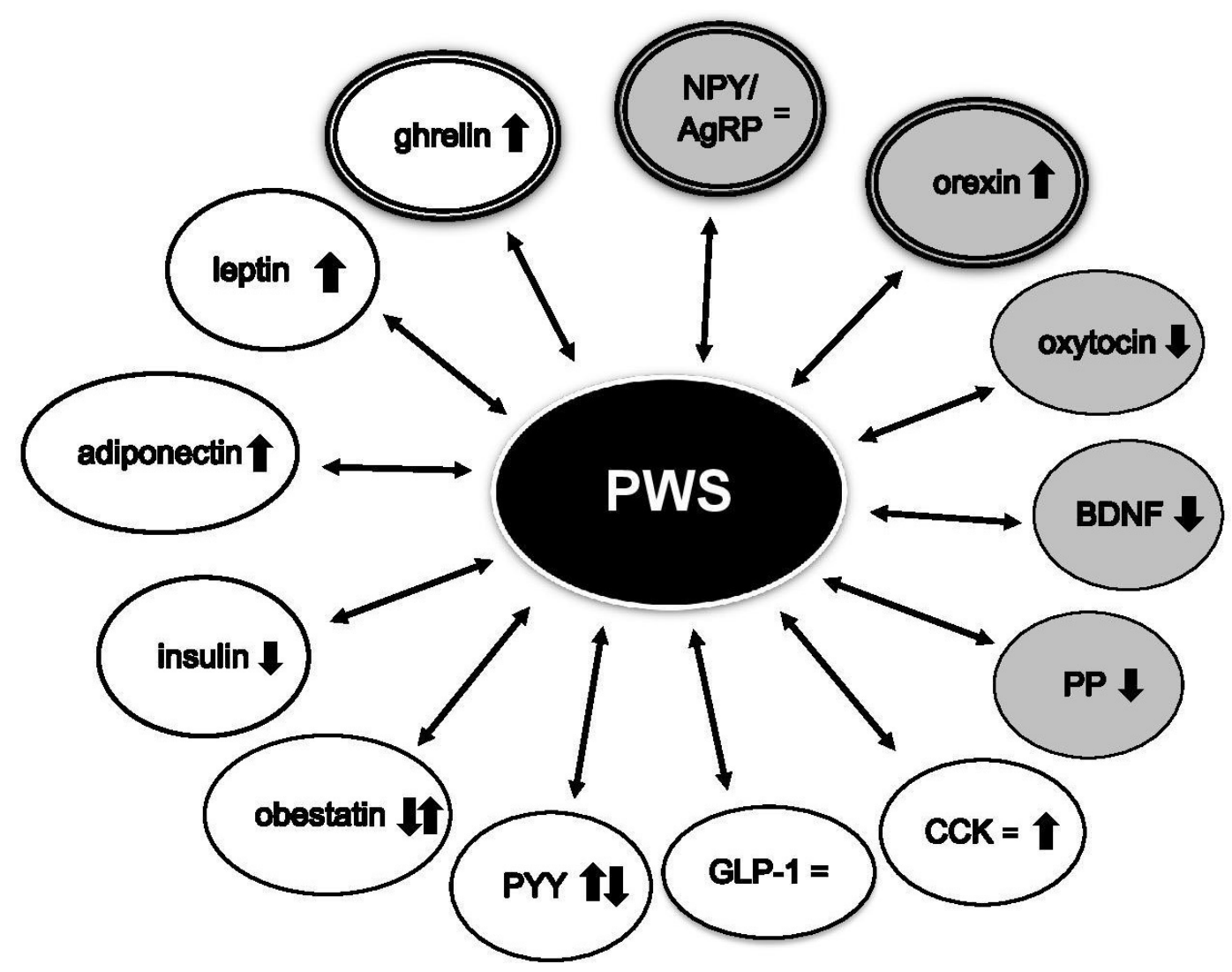

Figure I Circulating levels of orexigenic and anorexigenic hormones in PWS.

Notes: Orexigenic modulators are shown with a double circle, while the single circle represents anorexigenic stimuli. Gray circles represent neuromodulators of the central nervous system, while white circles represent peripheral stimulators of food intake. $\uparrow$ high; $\downarrow$ low; = normal; $\uparrow \downarrow$ low, normal, or high levels.

Abbreviations: AgRP, agouti-related peptide; BDNF, brain-derived neurotrophic factor; CCK, cholecystokinin; GLP-I, glucagon-like peptide I; NPY, neuropeptide Y; PP, pancreatic polypeptide; PWS, Prader-Willi syndrome; PYY, peptide YY. 
However, the basis for the abnormal eating behavior observed in PWS has not yet been understood. ${ }^{27}$

Among the anorexigenic hormones, markedly high levels of leptin in PWS have been reported, with a normal relationship between circulating levels of leptin and BMI. ${ }^{28}$ No significant difference was found both in total and in free leptin values among PWS and simple obesity, ${ }^{29,30}$ as well as no variation of leptin levels was observed in relation to the changing of PWS eating phenotype. ${ }^{28}$ Therefore, a causal role of leptin for obesity development in PWS seems to be ruled out.

Brain-derived neurotrophic factor (BDNF) is involved in the regulation of energy homeostasis, acting as a satiety signal downstream of leptin-melanocortin signaling. Reduced circulating BDNF levels have been observed in PWS subjects in comparison to weight-matched controls. In this respect, it has been suggested that low basal BDNF levels and lack of postprandial peak may contribute to the persistent hunger of PWS subjects after meals. ${ }^{31}$

Oxytocin is known to inhibit food intake and PWS is characterized by oxytocinergic dysfunction. Apart from the reduced hypothalamic oxytocin expressing neurons, ${ }^{20}$ abnormally low oxytocin levels in relation to the obesity have been found in PWS, ${ }^{32}$ suggesting a possible role of oxytocin in the abnormal eating behavior of the affected individuals.

The anorexigenic hormones glucagon-like peptide 1 (GLP-1) and peptide YY (PYY) are released in response to nutrient ingestion, reducing caloric intake in both normal weight and obese subjects. No difference in fasting and postprandial GLP-1 levels was reported in PWS subjects when compared to obese and lean controls. ${ }^{33,34}$ Data about basal PYY levels in PWS are still conflicting, and low, normal, or high fasting and postprandial concentrations have been demonstrated. ${ }^{35}$ A higher postprandial PYY increase compared to obese and lean controls was also evidenced. ${ }^{36}$ It is interesting to note that different rates of eating behavior seem to induce peculiar responses of anorexigenic gut peptides in PWS compared to simple obesity. In fact, fast feeding leads to higher concentrations of both GLP-1 and PYY, favoring the appearance of satiety in PWS adult patients, this pattern not being evident in obese controls. ${ }^{37}$ Moreover, reduced postprandial PYY secretion is detected in PWS when motivation to eat is induced by highly appetizing foods, suggesting a possible role of PYY agonists in the pharmacological strategy in these patients. ${ }^{38}$

Cholecystokinin $(\mathrm{CCK})$ is a satiety hormone secreted in response to food consumption and digestion. In PWS individuals, either normal ${ }^{39}$ or elevated ${ }^{40}$ fasting CCK concentrations were observed. Furthermore, similar CCK levels were found after exposure to food in PWS patients and in obese subjects. ${ }^{38,40}$

Pancreatic polypeptide (PP) exerts an anorexigenic effect after a protein meal, and reduced concentrations of fasting and postprandial PP have been found in PWS. ${ }^{28,41} \mathrm{~A}$ slight inhibition of food intake after PP administration was observed in females with PWS ${ }^{42}$ suggesting that a functional deficiency of PP may be present in these patients.

Obestatin is an anorexigenic peptide derived posttranslationally from preproghrelin. Since significantly higher levels of obestatin were detected in infants with PWS, it has been proposed that this hormone may contribute to their initial growth failure. ${ }^{43}$ These findings, however, were conflicting with other results. ${ }^{44}$

As previously reported, several reports have shown that PWS is characterized by a state of relative hypoinsulinemia despite severe obesity. Thus, it is possible that fasting and/ or postprandial hypoinsulinemia may be involved in the development of hyperphagia.

Adiponectin is an adipokine known to have significant effects on glucose and lipid metabolism, insulin sensitivity, and inflammation. In addition, adiponectin seems to be able to modulate appetite and energy homeostasis, acting on the central nervous system. ${ }^{45}$ Adiponectin may stimulate food intake in the fasting state in short-term experiments, as opposed to reducing food intake in the long term. ${ }^{46}$ In this context, it is of note that PWS subjects showed higher levels of adiponectin in comparison to obese controls. ${ }^{33}$

Few studies have investigated the role of the orexigenic acting neuropeptide Y (NPY)/agouti-related peptide (AgRP) neurons in the control of food intake in PWS. In this respect, no difference in plasma concentrations of NPY and AgRP has been previously found. ${ }^{47}$ More recently, it has been demonstrated that the lack of Snord1 16 in NPY neurons leads to the upregulation of NPY mRNA consistent with the food-seeking behavior, suggesting a crucial role of Snord116 in the control of NPY neuronal functions that could be altered in PWS.48

Orexin acts as an appetite stimulator, interacting with other neuropeptides to modulate food intake. Manzardo et $\mathrm{a}^{49}$ have found significantly higher levels of plasma orexin $A$ in PWS children compared with unrelated siblings, hypothesizing that dysregulation of the orexin system may contribute to an abnormal eating attitude in PWS.

High ghrelin levels have been described in PWS at all ages, both before the development of obesity and after the appearance of hyperphagia in older children and in adults. ${ }^{50}$ Due to its orexigenic action, hyperghrelinemia has been suggested as a potential cause of increased appetite and weight gain in PWS. ${ }^{51}$ The mechanisms underlying ghrelin dysregulation 
in this syndrome are currently unknown. It is of note that circulating ghrelin is present in both acylated and unacylated forms. The unacylated form has been shown to inhibit food intake, while acylated ghrelin exerts an orexigenic effect. In this context, an intrinsic defect has been hypothesized in the acylated ghrelin/unacylated ghrelin ratio in circulation, resulting in a relative acylated ghrelin deficit in PWS infants and a subsequent excess in later life that correlates with the switch in feeding behavior. ${ }^{52}$ However, the suppression of ghrelin achieved with acute or chronic administration of somatostatin in PWS is not associated to a positive effect on food intake and body weight reduction, ${ }^{28}$ indicating that the role of ghrelin in hyperphagia of these patients remains to be clarified.

\section{Comorbidities of obesity in PWS}

Obesity is a major cause of premature morbidity and mortality in PWS. ${ }^{53}$ Without supervision, PWS patients may suddenly die as a result of choking (above all during bouts of heavy eating $)^{54}$ or stomach rupture and necrosis. ${ }^{55}$ On the other hand, the long-term prognosis is significantly worsened by complications usually linked to morbid obesity.

Comorbidities commonly associated with severe weight excess in PWS include respiratory problems (pulmonary embolism, respiratory failure, pulmonary hypertension) and sleep disorders (obstructive sleep apnea), right heart dysfunction, myocardial infarction, arterial hypertension, steatohepatitis, gallstones, deep venous thromboses, and chronic leg edema. ${ }^{10,12,53,56}$ Overall, respiratory and cardiac diseases account for $38 \%$ and $16 \%$ of deaths in these patients, respectively. ${ }^{57}$ Taking into account the metabolic profile, hyperlipidemia is reported in about a third of the subjects. ${ }^{58}$ PWS subjects show a high prevalence of altered glucose metabolism (24.4\%), including type 2 diabetes mellitus (T2DM) with multiorgan failure, that appears more common in obese and adult subjects. ${ }^{59}$ In this context, metabolic syndrome (MS) is a strong risk factor for T2DM, as well as for atherosclerotic cardiovascular disease, and MS might be potentially one of the mechanisms responsible for excessive mortality in PWS. Current findings suggest the main role that obesity status plays on the development of MS in PWS, both in the pediatric age ${ }^{17}$ and in adult patients. ${ }^{60}$ It follows that prevention of obesity remains the most important goal of the PWS therapeutic strategy.

\section{Current standard therapies Nutritional management and behavioral modifications in PWS}

Improvement in weight control remains the most important goal of any PWS treatment program, but the management of obesity in these patients is not easy.
Because of lack of fullness, when unlimited access to food is given, PWS patients are capable of consuming huge amounts of calories. Moreover, PWS subjects gain weight if they consume the same number of calories as other individuals of the same age and height, due to sarcopenia and the resulting reduced REE. Therefore, properly planned nutritional treatment is an extremely important tool in such patients. In this context, a correct food intake must be able to prevent malnutrition in the first months of life. ${ }^{61}$

Subsequently, a program of a low-calorie, well-balanced diet and close supervision to minimize food stealing must be established from the first months of life in order to prevent obesity and its consequences, in addition to exercise and behavior modification. ${ }^{9,62,63}$

Consultation with a dietician (nutritionist) and close follow-up from infancy through adulthood are always necessary, providing the needed nutrients while restricting calories in order to maintain a healthy weight.

Due to the decreased REE in PWS, caloric needs of infants and children with PWS are typically 60\%-80\% of the recommended daily allowance, which enable them to maintain a stable body weight. ${ }^{61,64}$

Many studies have been performed on diet restriction and physical activities in PWS, with different and sometimes conflicting results. ${ }^{65-67}$

It has been demonstrated that before these children begin to develop excessive weight gain, which typically occurs at the age of $\sim 2$ years, an energy-restricted and well-balanced diet ( $~ 30 \%$ fat, $45 \%$ carbohydrates, and $25 \%$ protein, and at least 20 g of fiber per day) can help reduce weight gain and fat mass. ${ }^{68}$

In later ages, strategies to cope with their longing for food, their asking for more food, and their food seeking behavior should be individually developed, taking into account that PWS individuals require fewer calories (40\%-70\% reduction) compared with nonobese controls. ${ }^{69}$

Other weight management strategies should include weekly weighing, complete control of food intake, environmental barriers to food access (such as locking the kitchen, refrigerator, and/or cupboards to avoid food stealing), and restriction to money and diet.

PWS patients should be educated to know what to expect in order to minimize anxiety and to manage behavioral alterations, developing a feeling of "food security" as developed by Pittsburgh Patnership. ${ }^{70}$

Management also means locks on pantries, fridges, food cupboards - not straight away, but when food seeking becomes apparent. Although this might seem antiquated and unfair, it is incredibly helpful to the person with PWS to know that food is secure and is not a temptation to them. 
The support of teachers, grandparents, carers, and family friends is needed to help ensure that children adhere to prescribed diet, eating routines, healthy eating behaviors, and daily exercise. This is not always easy because the diet is very restrictive and because a child with PWS does not feel satisfied after eating. It is mandatory to resist giving food treats, even if the child does not look overweight.

Children with PWS usually have less muscle mass and lower muscle tone than other children, and are therefore more prone to avoid physical activity. ${ }^{71}$ Subjects with PWS of all ages with low muscle mass (lean body mass) will burn less energy throughout the day than others with high muscle mass.

Therefore, physical exercise should be part of the regular routine in these patients, together with occupational and behavioral therapy. Daily exercise should be mandatory and should begin at an early age. There are all types of exercises designed to strengthen muscles and therefore if a PWS child is under a physiotherapist, one should make sure that an early exercise program is started. ${ }^{72}$

Exercise should be encouraged at all times - even "hidden" exercise, such as parking further away in the supermarket carpark, climbing stairs, helping push the supermarket trolley etc, is recommended in PWS during their entire lifetime.

In any case, prevention of obesity is very important in these patients from the very first years of life because when obesity has already developed it is not possible to maintain a control of food intake.

In fact, dietary, physical activity and behavior interventions have not been demonstrated to result in significant long-term success due to food-seeking behavior and lack of appetite control in a high percentage of patients with PWS. Finally, it is necessary to keep the patient occupied with recreational activities that distract him from food.

In Table 1, some tips on good eating behaviors for PWS patients are reported.

\section{Pharmacological treatment of obesity in PWS}

Pharmacotherapy options in patients with PWS are very limited, and to date no medications have shown long-term effectiveness in controlling appetite in PWS patients. ${ }^{73,74}$

The drugs used over time targeted lipid digestion/absorption (orlistat), carbohydrate metabolism (metformin), increase of energy expenditure (sibutramine, lorcaserin, bupropion, naltrexone), and food seeking behavior (topiramate, rimonabant, somatostatin analog, exenatide, liraglutide) (Table 2).
Table I Tips on good eating behaviors for Prader-Willi syndrome patients

I. Provide a wide choice of healthy foods, especially a large variety of vegetables, salads, fruits, and lean meat.

2. Above all drink plenty of water, and encourage the patient to do the same.

3. Prepare smaller portions of food.

4. Avoid giving extra treats (like biscuits and candy etc) so that the patient does not get used to the "sweet taste."

5. Do not restrict food treats as a form of punishment and avoid food rewards; try to adopt other types of recompenses.

6. Stimulate and incite the patient to do physical exercise and other calorie consuming activities.

7. Create a daily program which includes all activities, exercise, meals, and breaks.

8. Always speak to the child before making any changes in daily routine.

9. Give instructions to the child regarding good food options.

10. Promote a strategy to stem continuous requests of food.

II. Approve and laud all good behavior with instant rewards (hugs, gadgets).

12. Do not struggle to make the child reason.

13. All carers, teachers, family friends involved should support the parents/chief carers of Prader-Willi syndrome patients.

14. A multifaceted approach is needed to control the food environment, behavior management, diet, and physical exercise.

15. Keep the patient occupied with recreational activities that distract $\mathrm{him} /$ her from the search for food.

Orlistat is a pancreatic lipase inhibitor and is useful for limiting fat absorption to up to $30 \%$ of ingested fats. Due to the peripheral mechanism of action, it has no central side effects and presents additional benefits on lipid profile and hypertension. ${ }^{75}$ Nevertheless, undigested fats change stools, which can limit in some cases the long-term compliance. Absorption of fat-soluble vitamins and $\beta$-carotene is decreased by orlistat therapy, with vitamin $\mathrm{D}$ being the most frequently affected; therefore, a supplement of these vitamins is required during long-term treatment.

Reports related to orlistat use in PWS subjects are scarce, with modest efficacy, poor compliance, and gastrointestinal side effects. ${ }^{76}$

Metformin is frequently used in PWS patients with $\mathrm{T} 2 \mathrm{DM}$ and/or insulin resistance. It seems that metformin may improve the sense of satiety and decrease anxiety about food in some individuals with PWS. In a pilot study performed in adults with PWS, metformin reduced appetite especially in females and in those with hyperinsulinemia, perhaps by increasing insulin sensitivity. ${ }^{77}$

Gastrointestinal problems can be frequent and may rarely lead to vitamin B12 deficiency.

Serotonin reduces food intake, and thus appropriate agonists for serotonin receptors are possible valuable drugs. 
Table 2 Medications used to treat weight loss and their effects in PWS

\begin{tabular}{|c|c|c|c|}
\hline Medications & Mechanism of action & Positive effects & Side effects \\
\hline - Orlistat & $\begin{array}{l}\text { Reversible inhibitor of gastric and } \\
\text { pancreatic lipases } \\
\text { (peripheral mechanism of action) }\end{array}$ & $\begin{array}{l}\text { Prevents } \sim 30 \% \text { of dietary fat from } \\
\text { being absorbed }\end{array}$ & $\begin{array}{l}\text { Malabsorption of fat-soluble vitamins, } \\
\text { severe diarrhea if the patient consumes a } \\
\text { lot of fat, steatorrhea }\end{array}$ \\
\hline - Metformin & $\begin{array}{l}\text { Insulin sensitizer; it may allow } \\
\text { insulin to reach its receptors in the } \\
\text { hypothalamus to stimulate satiety }\end{array}$ & $\begin{array}{l}\text { Improves sense of satiety and } \\
\text { decreases anxiety about food }\end{array}$ & $\begin{array}{l}\text { Gastrointestinal problems, lactic acidosis, } \\
\text { may lead to vitamin BI } 2 \text { deficiency }\end{array}$ \\
\hline - Sibutramine & $\begin{array}{l}\text { Unspecific inhibitor of serotonin and } \\
\text { norepinephrine reuptake }\end{array}$ & Increases energy expenditure & $\begin{array}{l}\text { Shortness of breath, increases blood } \\
\text { pressure and cardiovascular events, } \\
\text { mental health problems arising in some } \\
\text { individuals with PWS - withdrawn }\end{array}$ \\
\hline - Rimonabant & $\begin{array}{l}\text { Endocannabinoid } \mathrm{CBI} \text { receptor } \\
\text { antagonist (in central and peripheral } \\
\text { nervous systems) }\end{array}$ & $\begin{array}{l}\text { Decreases appetite and lipogenesis; } \\
\text { increases energy expenditure }\end{array}$ & $\begin{array}{l}\text { Anxiety and psychiatric side effects } \\
\text { (depression and even suicide - psychotic } \\
\text { reaction), disturbed sleep - withdrawn }\end{array}$ \\
\hline - Lorcaserin & $\begin{array}{l}\text { Highly selective serotonergic } \\
5 \text {-hydroxytryptamine }(5-\mathrm{HT}) 2 \mathrm{C} \\
\text { receptor agonist }\end{array}$ & $\begin{array}{l}\text { Beneficial effects on markers of } \\
\text { cardiovascular and diabetes risks; } \\
\text { limited weight loss efficacy }\end{array}$ & $\begin{array}{l}\text { Headache, infection, sinusitis, nausea, } \\
\text { depression, anxiety, and suicidal } \\
\text { thoughts, possible concerns of cancer } \\
\text { risks }\end{array}$ \\
\hline $\begin{array}{l}\text { - Naltrexone/bupropion } \\
\text { (in association) }\end{array}$ & $\begin{array}{l}\text { Opioid ( } \beta \text {-endorphin) receptor } \\
\text { antagonist + norepinephrine- } \\
\text { dopamine reuptake inhibitor } \\
\text { (increase in POMC activity in the } \\
\text { hypothalamic melanocortin system) }\end{array}$ & $\begin{array}{l}\text { Decreases hunger and increases } \\
\text { energy expenditure; improves skin } \\
\text { picking and behavior }\end{array}$ & $\begin{array}{l}\text { Gastrointestinal problems, dry mouth, } \\
\text { headache, increased sweating, insomnia, } \\
\text { and tremor; blood pressure often } \\
\text { increases }\end{array}$ \\
\hline - Growth hormone & $\begin{array}{l}\text { Increases muscle mass, stamina, and } \\
\text { bone mineral density, and decreases } \\
\text { body fat mass }\end{array}$ & $\begin{array}{l}\text { Improves development, behavior, } \\
\text { flexibility, motor performance, and } \\
\text { alertness }\end{array}$ & $\begin{array}{l}\text { Contraindicated in children with PWS } \\
\text { who are severely obese or have severe } \\
\text { respiratory impairment }\end{array}$ \\
\hline - Octreotide & $\begin{array}{l}\text { Long-acting somatostatin analog - } \\
\text { decreases fasting ghrelin }\end{array}$ & $\begin{array}{l}\text { No significant effects on weight, } \\
\text { behavior, or appetite }\end{array}$ & Acute psychoses \\
\hline - Topiramate & $\begin{array}{l}\text { Modulates } \mathrm{Na}^{+} \text {channels, GABA, and } \\
\text { AMPA/kainite receptors }\end{array}$ & $\begin{array}{l}\text { Improves food seeking behavior, } \\
\text { skin picking, and atypical psychoses }\end{array}$ & $\begin{array}{l}\text { Fatigue, dizziness, paresthesia, } \\
\text { somnolence, ataxia, sedation, } \\
\text { nephrolithiasis, mild confusion }\end{array}$ \\
\hline - Liraglutide or exenatide & $\begin{array}{l}\text { Glucagon-like polypeptide-I } \\
\text { receptor agonists, increases insulin } \\
\text { secretion }\end{array}$ & $\begin{array}{l}\text { Improves glycemic control, } \\
\text { increases satiety, and reduces body } \\
\text { weight }\end{array}$ & $\begin{array}{l}\text { Nausea, delayed gastric emptying, } \\
\text { significant increase in heart rate }\end{array}$ \\
\hline
\end{tabular}

Abbreviations: PWS, Prader-Willi syndrome; POMC, proopiomelanocortin; GABA, gamma-aminobutyric acid.

Among these, sibutramine, as an unspecific inhibitor of serotonin and norepinephrine reuptake, was proposed in PWS patients after considering favorable results obtained in obese patients and in hypothalamic obesity. ${ }^{78}$ Unfortunately, due to its adverse cardiovascular effects it was withdrawn from the market a few years ago. ${ }^{79}$

Lorcaserin is a high-affinity selective agonist of the serotonin $2 \mathrm{C}$ receptor and is effective in inducing $\geq 5 \%$ weight loss in obese individuals. In addition to weight loss, as compared with old unspecific serotonin agonists, lorcaserin had beneficial effects on surrogate markers of cardiovascular and diabetes risk, including decreases in blood pressure values, heart rate, total and LDL cholesterol, fasting glucose, insulin levels, C-reactive protein, and fibrinogen ${ }^{80,81}$ Currently, there are no studies on PWS obesity using lorcaserin. In this context, a short-term positive effect of fenfluramine, another serotonin releasing agent, in patients with PWS has been previously reported. ${ }^{82}$ Thus, lorcaserin may hypothetically be considered as a future tool for control of hyperphagia in these patients. ${ }^{83}$

Rimonabant blocks endocannabinoid CB1 receptor in the central and peripheral nervous systems and other key cells involved in body energy metabolism and has been tried for the treatment of obesity in adult subjects. Rimonabant promoted weight loss by multiple proposed mechanisms, including decreased appetite and lipogenesis, and increased energy expenditure. The effects in PWS adults are similar in terms of weight loss and decreased appetite, but psychiatric side effects (anxiety, disturbed sleep, paranoid ideation, and psychotic reactions) limited its use..$^{84}$

However, the drug was withdrawn from the market in January 2009, following increased incidence of major depression and even suicide in treated subjects. 
Bupropion is a sympathomimetic drug that inhibits reuptake of catecholamines, dopamine and norepinephrine, and activates central melanocortin pathways in the arcuate nucleus ( $\alpha$-MSH and $\beta$-endorphin secretion); it decreases hunger and increases energy expenditure. It is primarily used as an atypical antidepressant and smoking cessation aid, and also in hyperactivity disorder with limited success. Naltrexone, an opioid receptor antagonist, blocks $\beta$-endorphin inhibition of $\alpha-\mathrm{MSH}$ release, and decreases hunger and increases energy expenditure.

Naltrexone and bupropion have independent actions in the brain's reward system and in proopiomelanocortin (POMC) neurons of the hypothalamus, but it seems that the systemic effects of this combination produce a synergistic effect of decreasing food intake and weight. ${ }^{85}$

The combination naltrexone-bupropion has recently been used in the treatment of obesity, ${ }^{86}$ but not in PWS patients. Previous data on the use of naltrexone alone in PWS children and adolescents showed a slight improvement in weight control, skin picking, and behavior. ${ }^{87,88}$ Therefore, this treatment needs to be examined further in long-term clinical trials involving PWS patients of all ages.

GH deficiency is present in almost all PWS children, as well as in a significant percentage of adults. ${ }^{89} \mathrm{GH}$ therapy is effective in increasing height, decreasing body fat, increasing fat-free mass, and improving muscle strength. In addition, several studies suggest positive effects on development and behavior, including mental speed, flexibility, motor performance, and increased alertness. ${ }^{90,91}$ If started at a young age, GH therapy, along with good dietary control, may delay obesity and fat mass and may prevent the development of the typical facial appearance. ${ }^{92}$

However, GH administration seems to be ineffective in decreasing appetite and food seeking behaviors. Nevertheless, long-term observational studies reviewing treatment with GH showed improvement in body mass composition and reduction in BMI, even if PWS subjects treated with GH were still obese. ${ }^{93}$ Eight years of GH treatment in 60 children with PWS significantly lowered the BMI standard deviations score (SDS) in comparison to baseline. ${ }^{94}$ Although the percentage of fat SDS improved during the first year of GH treatment, it returned to the baseline level after 8 years of therapy. A possible explanation for this phenomenon could be that the gradual increase in percentage of fat seen over the years during the natural clinical course of PWS cannot be fully restrained by GH treatment.

Based on elevated ghrelin concentrations found in individuals with PWS, in a 56-week study octreotide (long-acting somatostatin analog) significantly decreased fasting ghrelin concentrations (both acylated ghrelin, known to stimulate hunger, and unacylated ghrelin), but did not significantly affect weight, behavior, or appetite in nine adolescents with PWS. ${ }^{95}$

In addition, it seems that both short-acting and slow release formulations of somatostatin analogs are not an effective therapy for obesity in PWS. ${ }^{96}$

In PWS, recurrent psychoses are relatively frequent, especially in patients with UPD, after adolescence. These episodes have a subacute onset with complete recovery and include an increase of psychomotor symptoms similar to catatonia. Gamma-aminobutyric acid (GABA) neural circuits dysfunctionality is involved in both PWS and catatonia. ${ }^{97}$

Treatment of these atypical psychoses could include topiramate. This antiepileptic drug has modulator effects on $\mathrm{Na}^{+}$channels, GABA, and AMPA/kainate receptors and is also known to affect food seeking behavior. In an 8-week open-label study in patients with PWS, topiramate had no significant effect on appetite and BMI, but, surprisingly, resulted in a clinically significant improvement in self-injury (ie, skin-picking) that is a characteristic of this syndrome. ${ }^{98}$

Treatment with GLP-1 agonists (exenatide, liraglutide) has been shown to have beneficial effects on weight, satiety, and glycemic control in PWS adults with T2DM..$^{99,100}$ These medications have been well-tolerated (less bloating, nausea, and vomiting) in PWS patients, possibly due to the higher threshold for pain and nausea in these patients. However, caution must be used due to potential side effects of delayed gastric emptying and pre-existing risk for gastric rupture in the population. ${ }^{101}$

In a pilot study in adult PWS and obese control patients, a single dose of $10 \mu \mathrm{g}$ of the GLP-1 receptor agonist exenatide increased satiety independently of the measured appetite hormones, lowered glucose before and during a control meal, and increased the insulin secretion rate in both groups. ${ }^{99} \mathrm{It}$ is noteworthy that side effects were absent in PWS.

The efficacy of long-term treatment with subcutaneous liraglutide (recommended daily dosage between 1.2 and 1.8 $\mathrm{mg}$ ) or exenatide was evaluated in adult PWS patients with T2DM. During 24 months of therapy, a tendency toward decreased BMI, HbA1c, and waist circumference, and a significant decrease of mean glycemia during continuous glycemic monitoring was detected, especially during the first 12 months. ${ }^{102}$

The beneficial effects of liraglutide on body weight and metabolic control could be further confirmed by the chronic use of the new $6 \mathrm{mg} / \mathrm{mL}$ formulation (maximum dose $3 \mathrm{mg}$ / day). 
The effectiveness of various food supplements for the treatment of hyperphagia is not confirmed by scientific evidence and therefore their use is not justified in such patients.

Several medications are in clinical trials for PWS including beloranib (Zafgen Inc, Boston, MA, USA), RM-493 (Rhythm Pharmaceuticals, Boston, MA, USA), diazoxide (Soleno Pharmaceutics, Redwood City, CA, USA), AZP531 (Alizé Pharma, Ecully, France), intranasal oxytocin, and oxytocin analog (Ferring Pharmaceuticals, Saint-Prex, Switzerland). Each of these agents has a different target, ranging from affecting fat metabolism to directly influencing the hypothalamic pathways of appetite and satiety. ${ }^{103}$

Beloranib is a methionine aminopeptidase 2 (MetAP2) inhibitor that reduces fat biosynthesis and increases fat oxidation and lipolysis as well as metabolic and hormonal changes. In other words, it reduces the production of new fatty acid molecules by the liver and facilitates the conversion of stored fats into energy. It may also have a satiety effect on the hypothalamus. Beloranib and other MetAP2 inhibitors reduce hunger, food intake, and hyperphagia-related behaviors, with patients losing weight and feeling less hungry. ${ }^{104}$

This drug has produced significant weight loss and reduction of hyperphagia in a Phase 3 randomized trial of patients with PWS. ${ }^{105}$

However, both the Phase 3 PWS trial and a Phase 2 trial in people with severe obesity complicated by type 2 diabetes were blocked early following the death of two PWS patients due to pulmonary emboli. Furthermore, a small number of additional patients from both trials showed not fatal thrombotic events while taking beloranib.

Development of beloranib is now on clinical hold until further data and a risk mitigation strategy are discussed with the US Food and Drug Administration.

It is probable that the adverse events might be part of the syndrome in addition to the effects of the drug.

More recently, another MetAP2 inhibitor, ZGN1061, was recently investigated for the treatment of diabetes and obesity. ${ }^{106}$ The effects on endothelial cells proliferation and coagulation proteins seem greatly attenuated or absent, compared to beloranib.

Setmelanotide is a melanocortin-4 receptor (MC4R) agonist also known as RM-493. It is a peptide that binds with high affinity to the human MC4R and is efficient in activating it. Setmelanotide significantly increases REE and preferentially increased fat oxidation in obese individuals with minimal side effects and no effects on blood pressure. Clinical trials demonstrated promising weight loss with good tolerability. Setmelanotide potentially offers a mechanism- based treatment of obesity in POMC deficiency, which in effect provides a substitute for the absent melanocyte stimulating hormone. ${ }^{107}$

A Phase 2a trial (ClinicalTrials.gov: NCT02311673) evaluated the safety and efficacy of this drug in PWS in which reduced POMC activity (leptin-melanocortin pathway activity - MAGEL2 gene inactivated) was demonstrated.

The trial was recently completed in these patients but only modest changes in hyperphagia without changes in weight were obtained (unpublished data). For this reason, up to date, the results do not support moving directly to Phase 3 .

Diazoxide, which has been used for many years for hypoglycemic conditions with hyperinsulinism and hypertensive crises, opens the $\mathrm{K}_{\text {ATP }}$ channels in the brain, reducing the synthesis and secretion of appetite stimulatory neuropeptides, NPY and AgRP, thereby reducing hyperphagia. It may also amplify the effects of GABA on GABAnergic neurones and thereby limits the aggressive and other behavioral complications in PWS.

This drug seems to be of potential benefit for patients with PWS as it could reduce the excessive food intake mediated by orexigenic NPY and increase REE. ${ }^{108}$

A Phase 2 study (PC025 pilot study) with diazoxide choline controlled-release (DCCR) tablet has been completed in children with PWS, obtaining a reduction of appetite, improvement in cardiovascular risk factors, insulin sensitivity, and a reduction in waist circumference (suggestive of a loss of visceral fat). ${ }^{109}$ In this context, a multicenter Phase 3 clinical trial (ClinicalTrials.gov: NCT03440814) with DCCR for the treatment of PWS was initiated in May 2018.

As previously mentioned, several data suggest the existence of abnormalities of the oxytocin system in PWS. Thus, the administration of oxytocin may potentially have some effects on appetite in PWS.

To date, five clinical trials have evaluated the efficacy of oxytocin in PWS, but the results are not univocal. Some authors have investigated the effects of oxytocin on foodrelated and social behaviors of these patients with variable results. The majority of studies have not shown significant improvement in food-related behaviors. ${ }^{110-112}$ On the contrary, an improvement in oral feeding skills has been observed in very young PWS infants receiving a short course of oxytocin within the first 6 months of life, ${ }^{113}$ possibly indicating that early administration of oxytocin can modify the natural history of feeding and feeding-behaviors in these subjects.

It is possible that factors associated with early intervention, placebo effects, experiment design, and dose regimens may account for these equivocal findings. Currently, however, there is no randomized controlled evidence convincing that 
intranasal oxytocin improves symptoms and hyperphagia in individuals with PWS. ${ }^{114}$ Recently, intranasal carbetocin, an oxytocin analog, was used in a prospective, randomized, double-blind trial in adolescents with PWS. The drug was well-tolerated and improved hyperphagia and behavioral symptoms in these patients. ${ }^{115}$

AZP-531 (livoletide), an unacylated ghrelin analog, was used in a multicenter, randomized, double-blind, placebocontrolled Phase 2 clinical trial in 47 PWS patients. ${ }^{116}$ With this treatment carried out for 2 weeks there was a significant improvement in food-related behaviors, supported by a reduction in hunger, as well as encouraging metabolic signals. In Phase 1 trials, this drug improved glycemic control and weight in non-PWS individuals with obesity and type 2 diabetes. Therefore, it may constitute a new treatment strategy to improve hyperphagia and metabolic issues in patients with PWS. However, these findings require further investigation in longer clinical trials.

\section{Non-pharmacological treatment of obesity in PWS}

Even though dietary measures and behavioral intervention are the gold standards in managing weight control in PWS, it is still necessary to achieve long-term improvement of hyperphagia. In order to improve the hyperphagic behaviors exhibited during the habitual dietary restriction by caregivers, it was recently demonstrated that an extract of the Indian cactus succulent Caralluma fimbriata is able to induce a significant reduction of hyperphagia modifying appetite behavior within a cohort of PWS children and adolescents. ${ }^{117}$

Based on the positive effects of intraperitoneal oleoylethanolamide administration in reducing food intake in Magel2KO, other authors have recently suggested a possible therapeutic use of this naturally occurring lipid in the management of PWS. ${ }^{23}$

\section{Deep brain stimulation (DBS)}

Based on neuroanatomical results that have recently emerged in the understanding of obesity in PWS patients and given the linked neural reward circuit dysfunction, DBS could represent, in the near future, another possible treatment modality in these particular patients. ${ }^{118}$

Some devices that are currently being tested also may reduce appetite and improve food-related behavior in individuals with PWS, including transcranial direct current stimulation and vagal nerve stimulators. ${ }^{119}$ These techniques seem to provide a safe, painless, inexpensive, nonrestrictive, and noninvasive method to modify neuronal functioning and to positively influence the cognitive process.

\section{Bariatric surgery}

Due to mounting evidence of the adverse long-term consequences of severe obesity coupled with the poor efficacy of nonsurgical options for weight loss, and a demonstrated safety and efficacy record of laparoscopic bariatric procedures in adult obese patients, there has been increasing interest in bariatric surgery also for PWS and severe obesity. ${ }^{120,121}$ It has been recommended that adolescents with $\mathrm{BMI} \geq 35 \mathrm{~kg} / \mathrm{m}^{2}$ and severe comorbidities that have significant short-term effects on health, such as moderate to severe obstructive sleep apnea, T2DM, pseudotumor cerebri, or severe and progressive steatohepatitis, or BMI $\geq 40 \mathrm{~kg} / \mathrm{m}^{2}$ with more minor comorbidities can be considered as candidates for bariatric surgery. ${ }^{122}$

Currently, the most widely performed procedures in adolescents and adults (without PWS) are Roux-en-Y gastric bypass (RYGB), sleeve gastrectomy (SLG), and the adjustable gastric band (AGB). ${ }^{123}$ Recent data suggest that SLG may be a safe alternative to RYGB, probably with fewer nutritional risks. SLG has the advantage of avoiding a foreign body and potential associated complications. It can be performed as the first step of a biliopancreatic diversion (BPD). ${ }^{124}$

To date, bariatric surgery experience in PWS is limited, and different bariatric procedures have been used with varying success. ${ }^{125,126}$ It is noteworthy that not all bariatric procedures are applicable for PWS subjects with obesity. ${ }^{127}$

The AGB procedure is not useful for patients with PWS. Malabsorptive procedures such as BPD are not always recommended for PWS as a first choice due to lack of safety data and also because of long-term nutritional complications. ${ }^{128}$

Mini-gastric bypass (MGB) was recently used in the management of morbid obesity in PWS. ${ }^{129}$ No nutritional impairment, weight regain, or need for revision surgery was recorded. MGB appeared to provide effective weight reduction in PWS without any significant nutritional impairment or weight regain.

Bariatric surgery in PWS is able to induce significant weight loss in the majority of cases, within the first years after surgery, but it is not always able to guarantee long-term weight loss maintenance. ${ }^{130}$ In addition, the risks and benefits of weight-loss surgery for individuals with syndromic obesity (such as PWS) have not been adequately explored, and information about long-term outcomes is limited. In this context, some authors believe that bariatric surgery could 
be contraindicated in this population, because it is often not accompanied by a decrease in appetite that occurs in typical individuals with obesity. ${ }^{131}$

Furthermore, the increased risk of gastric rupture in PWS could be exacerbated by bariatric surgery.

A study has indicated that $3 \%-6 \%$ of mortality in PWS is due to gastric necrosis as a result of severe gastric distension following binges of food intake. ${ }^{55}$

However, to date, this complication has never been described after bariatric surgery, ${ }^{125}$ even if the lack of longterm prospective studies does not exclude the possibility that this harmful complication in PWS patients may occur.

Consequently, patients with severe hyperphagic behavior need to be screened and carefully evaluated before any surgery is considered, in order to minimize the risk of postsurgery complications. Parents and caregivers should be aware of any suspicious sign or symptoms of possible gastric rupture or necrosis, such as vomiting and abdominal pain, that can be treated successfully with early identification.

In spite of this, obesity-related diseases such as diabetes and obstructive sleep apnea, as well as a quality of life, improved after surgically induced weight loss in PWS subjects. ${ }^{125}$ For this reason, bariatric surgery may represent a sign of hope for these patients and should be considered when dealing with life-threatened PWS patients.

Weight loss surgery for PWS should, however, be performed in the context of a multidisciplinary program with specific expertise in genetic obesity, bariatric surgery, nutrition, and psychology. Careful assessment, family involvement, and follow-up in a multidisciplinary setting are vital for the success of surgery. In fact, before opting for bariatric surgery, which is, however, an irreversible treatment, parents and/or patients need to know its benefits, risks of morbidity and mortality, and psychological effects. Moreover, it is necessary to bear in mind that lifelong supplementation with vitamins and minerals is mandatory for all patients undergoing any bariatric procedure, in order to avoid development of nutritional complications secondary to reduced intake, mild malabsorption, or both. ${ }^{132}$

From our experience, laparoscopic SLG would be a good option for PWS patients and should be performed in obese patients with a heightened danger of mortality, because it is almost always safe, and when no other effective alternative therapies are available. In some cases, after surgery appetite can be reduced and the patient is satisfied first.

BioEnterics ${ }^{\circledR}$ Intragastric Balloon (Allergan, Irvine, CA, USA) is another procedure also used in some patients with
PWS, wherein a gastric balloon is placed in the stomach for 6-7 months. ${ }^{133}$ Only modest weight loss was obtained together with complications in some cases. It could be more useful if used in the preparation of bariatric surgery (ie, SLG). ${ }^{134}$

In conclusion, evidence regarding bariatric surgery appears to provide effective weight reduction in many patients with PWS. However, more robust, controlled, prospective studies with a longer follow-up are required in order to define the efficacy of these procedures in PWS patients. ${ }^{135}$

\section{Current and future perspectives}

Currently, treatment of obesity in PWS is very difficult; therefore, the prevention of obesity in PWS subjects is of primary importance. Early institution of multidisciplinary care and parental education enable a significant number of children to keep their weight within a healthy range. Differently from older patients, early diagnosis of the syndrome now allows proper management to be designed to avoid obesity, through the introduction of a low-calorie and well-balanced diet together with appropriate psychological and behavioral counseling for the family. A discussion with parents immediately after birth on the unavoidable hyperphagia is essential, allowing them to acquire the ability to set limits and control food intake, as well as to promote physical activity.

Regular recreational activities are very useful to distract the patient from the search for food. It is mandatory that all children with PWS should begin a weight management program before the onset of hyperphagia.

Once obesity has developed, strategies for managing excess weight in PWS do not simply include a diet, but require a comprehensive multidisciplinary approach with establishment of rigid structures to limit food intake and promote supervised physical activity. Adequate management of obesity is also necessary to avoid major morbidities and increased mortality across the life span. In this context, rigorous supervision of obese PWS patients together with restriction of access to food and money and regular exercise can sometimes achieve good control of weight, reducing the onset of obesity-related complications.

However, lifestyle interventions are often ineffective, particularly in older PWS patients and in those that have received a late diagnosis. Especially in these patients, the possibility of discovering a drug to treat obesity is one of the most important challenges for future research. In fact, the greater majority of drugs currently available have been proved to be ineffective to treat hyperphagia and the resulting 
excessive weight gain with the promising exception of GLP-1 agonists.

In this light, the renewed interest of pharmaceutical companies in the development of new molecules for the therapy of genetic obesity is noteworthy. Trials currently underway on several new drugs in PWS patients (ie, setmelanotide, GLP-1 agonists, AZP-531, oxytocin, diazoxide, etc) show promising results, giving rise to much hope in the not too distant future.

Since specific medical treatment has not yet been discovered to alleviate the problem of obesity, sometimes, bariatric surgery in PWS could be considered for the control of morbid obesity. When dietary, behavioral, and pharmacological approaches fail, surgery could represent a valid therapeutic option in selected cases and in the presence of severe and progressive obesity with serious comorbidities.

Nevertheless, it is important to keep in mind that individuals with PWS have psychiatric issues, organic limitations (defect in satiety, altered pain threshold, abnormal gastric homeostasis, and decreased ability to vomit), ${ }^{131}$ and the need for close nutritional monitoring after bariatric procedures that, as a whole, can make the surgical intervention useless or harmful. In this regard, it would be optimal to have drugs which are able to obtain a substantial improvement in the eating patterns/behavior aspects before performing surgery.

In this light, however, appropriate surveillance is needed to assess the long-term outcome of surgery, both in terms of maintaining weight loss and resolving comorbidity, as well as to evaluate the appearance of complications related to these procedures. A psychologist and a dietician should always be present at each postoperative visit.

In conclusion, the treatment of obese PWS patients requires a multidisciplinary approach, from a pediatrician, endocrinologist, dietician, clinical geneticist, physical therapist, psychiatrist, and surgeon, in order to provide appropriate care for the complex phenotype of PWS patients. No single treatment has proven benefits, but an extended life-span and a better quality of life can be obtained by cooperation between the experts involved.

\section{Acknowledgments}

We would like to thank Dr Alessio Convertino who contributed to the bibliographic collection and for the drafting of the tables. We are also grateful to Diana Skeats for revising the English text.

\section{Disclosure}

The authors report no conflicts of interest in this work.

\section{References}

1. Cassidy SB, Schwartz S, Miller JL, Driscoll DJ. Prader-Willi syndrome. Genet Med. 2012;14(1):10-26.

2. Lionti T, Reid SM, White SM, Rowell MM. A population-based profile of 160 Australians with Prader-Willi syndrome: trends in diagnosis, birth prevalence and birth characteristics. Am JMed Genet A. 2015;167(2):371-378.

3. Butler MG, Manzardo AM, Forster JL. Prader-Willi syndrome: clinical genetics and diagnostic aspects with treatment approaches. Curr Pediatr Rev. 2016;12(2):136-166.

4. Cho SY, Ki CS, Sohn YB, et al. The proportion of uniparental disomy is increased in Prader-Willi syndrome due to an advanced maternal child bearing age in Korea. J Hum Genet. 2013;58(3):150-154.

5. Angulo MA, Butler MG, Cataletto ME. Prader-Willi syndrome: a review of clinical, genetic and endocrine finding. J Endocrinol Invest. 2015;38(12):1249-1263.

6. Heksch R, Kamboj M, Anglin K, Obrynba K. Review of Prader-Willi syndrome: the endocrine approach. Transl Pediatr. 2017;6(4):274-285.

7. Tauber M, Hauffa BP. The clinical picture of PWS: childhood. In: Hoybye C, editor. Prader-Willi Syndrome. New York: Nova Science Publishers; 2013:45-56.

8. Gunay-Aygun M, Schwartz S, Heeger S, O'Riordan MA, Cassidy SB. The changing purpose of Prader-Willi syndrome clinical diagnostic criteria and proposed revised criteria. Pediatrics. 2001;108(5):E92.

9. Goldstone AP, Holland AJ, Hauffa BP, Hokken-Koelega AC, Tauber M; Speakers Contributors at the Second Expert Meeting of the Comprehensive Care of Patients with PWS. Recommendations for the diagnosis and management of Prader-Willi syndrome. $J$ Clin Endocrinol Metab. 2008;93(11):4183-4197.

10. Manzardo AM, Loker J, Heinemann J, Loker C, Butler MG. Survival trends from the Prader-Willi Syndrome Association (USA) 40-year mortality survey. Genet Med. 2018;20(1):24-30.

11. Diene G, Mimoun E, Feigerlova E, et al. Endocrine disorder in children with Prader-Willi syndrome - data from 142 children of the French database. Horm Res Paediatr. 2010;74(2):121-128.

12. Grugni G, Crinò A, Bosio L, et al; Genetic Obesity Study Group of Italian Society of Pediatric Endocrinology and Diabetology (ISPED). The Italian National Survey for Prader-Willi syndrome: an epidemiologic study. Am J Med Genet A. 2008;146:861-872.

13. Sinnema M, Maaskant MA, van Schrojenstein Lantman-de Valk HM, et al. Physical health problems in adults with Prader-Willi syndrome. Am J Med Genet A. 2011;155(9):2112-2124.

14. Miller JL, Lynn CH, Driscoll DC, et al. Nutritional phases in PraderWilli syndrome. Am J Med Genet A. 2011;155(5):1040-1049.

15. Bekx MT, Carrel AL, Shriver TC, Li Z, Allen DB. Decreased energy expenditure is caused by abnormal body composition in infants with Prader-Willi syndrome. J Pediatr. 2003;143(3):372-376.

16. Goldstone AP, Thomas EL, Brynes AE, et al. Visceral adipose tissue and metabolic complications of obesity are reduced in Prader-Willi syndrome female adults: evidence for novel influences on body fat distribution. J Clin Endocrinol Metab. 2001;86(9):4330-4338.

17. Brambilla P, Crinò A, Bedogni G, et al; Genetic Obesity Study Group of the Italian Society of Pediatric Endocrinology and Diabetology (ISPED). Metabolic syndrome in children with Prader-Willi syndrome: the effect of obesity. Nutr Metab Cardiovasc Dis. 2011;21(4): 269-276.

18. Talebizadeh Z, Butler MG. Insulin resistance and obesity-related factors in Prader-Willi syndrome: comparison with obese subjects. Clin Genet. 2004;67(3):230-239.

19. Bedogni G, Grugni G, Tringali G, Marazzi N, Sartorio A. Does segmental body composition differ in women with Prader-Willi syndrome compared to women with essential obesity? $J$ Endocrinol Invest. 2015;38(9):957-961.

20. Swaab DF. Prader-Willi syndrome and the hypothalamus. Acta Paediatr Suppl. 1997;86(423):50-54. 
21. Xu M, Zhang Y, von Deneen KM, Zhu H, Gao J-H. Brain structural alterations in obese children with and without Prader-Willi syndrome. Hum Brain Mapp. 2017;38(8):4228-4238.

22. Polex-Wolf J, Lam BYH, Larder R, et al. Hypothalamic loss of Snord116 recapitulates the hyperphagia of Prader-Willi syndrome. $J$ Clin Invest. 2018;128(3):960-969.

23. Igarashi M, Narayanaswami V, Kimonis V, et al. Dysfunctional oleoylethanolamide signaling in a mouse model of Prader-Willi syndrome. Pharmacol Res. 2017;117:75-81.

24. Dimitropoulos A, Schultz RT. Food-related neural circuitry in PraderWilli syndrome: response to high- versus low-calorie foods. J Autism Dev Disord. 2008;38(9):1642-1653.

25. Zhang Y, Wang J, Zhang G, et al. The neurobiological drive for overeating implicated in Prader-Willi syndrome. Brain Res. 2015;1620:72-80.

26. Pujol J, Blanco-Hinojo L, Esteba-Castillo S, et al. Anomalous basal ganglia connectivity and obsessive-compulsive behaviour in patients with Prader-Willi syndrome. J Psychiatry Neurosci. 2016;41(4):261-271.

27. Khan MJ, Gerasimidis K, Edwards CA, Shaikh MG. Mechanisms of obesity in Prader-Willi syndrome. Pediatr Obes. 2018;13(1):3-13.

28. Goldstone AP, Holland AJ, Butler JV, Whittington JE. Appetite hormones and the transition to hyperphagia in children with Prader-Willi syndrome. Int J Obes (Lond). 2012;36(12):1564-1570.

29. Proto C, Romualdi D, Cento RM, Romano C, Campagna G, Lanzone A. Free and total leptin serum levels and soluble leptin receptors levels in two models of genetic obesity: the Prader-Willi and the Down syndromes. Metabolism. 2007;56(8):1076-1080.

30. Irizarry KA, Bain J, Butler MG, et al. Metabolic profiling in PraderWilli syndrome and non syndromic obesity: sex differences and the role of growth hormone. Clin Endocrinol (Oxf). 2015;83(6): 797-805.

31. Bueno M, Esteba-Castillo S, Novell R, et al. Lack of postprandial peak in brain-derived neurotrophic factor in adults with Prader-Willi syndrome. PLoS One. 2016;11(9):e0163468.

32. Höybye C, Barkeling B, Espelund U, Petersson M, Thorén M. Peptides associated with hyperphagia in adults with Prader-Willi syndrome before and during GH treatment. Growth Horm IGF Res. 2003;13(6):322-327.

33. Haqq AM, Muehlbauer MJ, Newgard CB, Grambow S, Freemark M. The metabolic phenotype of Prader-Willi syndrome (PWS) in childhood: heightened insulin sensitivity relative to body mass index. J Clin Endocrinol Metab. 2011;96(1):E225-E232.

34. Purtell L, Sze L, Loughnan G, et al. In adults with Prader-Willi syndrome, elevated ghrelin levels are more consistent with hyperphagia than high PYY and GLP-1 levels. Neuropeptides. 2011;45(4): 301-307.

35. Grugni G. The endocrine system in PWS. In: Hoybye C, editor. PraderWilli Syndrome. New York: Nova Science Publishers; 2013:107-119.

36. Bizzarri C, Rigamonti AE, Luce A, et al. Children with Prader-Willi syndrome exhibit more evident meal-induced responses in plasma ghrelin and peptide YY levels than obese and lean children. Eur $J$ Endocrinol. 2010;162(3):499-505.

37. Rigamonti AE, Bini S, Piscitelli F, et al. Hedonic eating in Prader-Willi syndrome is associated with blunted PYY secretion. Food Nutr Res. 2017;61(1):1297553.

38. Rigamonti AE, Bini S, Grugni G, et al. Unexpectedly increased anorexigenic postprandial responses of PYY and GLP-1 to fast ice cream consumption in adult patients with Prader-Willi syndrome. Clin Endocrinol (Oxf). 2014;81(4):542-550.

39. Butler MG, Carlson MG, Schmidt DE, Feurer ID, Thompson T. Plasma cholecystokinin levels in Prader-Willi syndrome and obese subjects. Am J Med Genet. 2000;95(1):67-70.

40. Paik KH, Jin D-K, Lee KH, et al. Peptide YY, cholecystokinin, insulin and ghrelin response to meal did not change, but mean serum levels of insulin is reduced in children with Prader-Willi syndrome. J Korean Med Sci. 2007;22(3):436-441.
41. Zipf WB, O’Dorisio TM, Cataland S, Dixon K. Pancreatic polypeptide responses to protein meal challenges in obese but otherwise normal children and obese children with Prader-Willi syndrome. J Clin Endocrinol Metab. 1983;57(5):1074-1080.

42. Berntson GG, Zipf WB, O’Dorisio TM, Hoffman JA, Chance RE. Pancreatic polypeptide infusions reduce food intake in Prader-Willi syndrome. Peptides. 1993;14(3):497-503.

43. Butler MG, Bittel DC. Plasma obestatin and ghrelin levels in subjects with Prader-Willi syndrome. Am JMed Genet A. 2007;143(5):415-421.

44. Park WH, Oh YJ, Kim GY, et al. Obestatin is not elevated or correlated with insulin in children with Prader-Willi syndrome. J Clin Endocrinol Metab. 2007;92(1):229-234.

45. Dridi S, Taouis M. Adiponectin and energy homeostasis: consensus and controversy. J Nutr Biochem. 2009;20(11):831-839.

46. Ma W, Huang T, Heianza Y, et al. Genetic variations of circulating adiponectin levels modulate changes in appetite in response to weightloss diets. J Clin Endocrinol Metab. 2017;102(1):316-325.

47. Goldstone AP, Unmehopa UA, Bloom SR, Swaab DF. Hypothalamic NPY and agouti-related protein are increased in human illness but not in Prader-Willi syndrome and other obese subjects. J Clin Endocrinol Metab. 2002;87(2):927-937.

48. Qi Y, Purtell L, Fu M, et al. Snord116 is critical in the regulation of food intake and body weight. Sci Rep. 2016;6(1):18614.

49. Manzardo AM, Johnson L, Miller JL, Driscoll DJ, Butler MG. Higher plasma orexin A levels in children with Prader-Willi syndrome compared with healthy unrelated sibling controls. Am J Med Genet A. 2016;170(9):2328-2333.

50. Feigerlová E, Diene G, Conte-Auriol F, et al. Hyperghrelinemia precedes obesity in Prader-Willi syndrome. J Clin Endocrinol Metab. 2008;93(7):2800-2805.

51. Irizarry KA, Miller M, Freemark M, HaqqAM. Prader Willi syndrome: genetics, metabolomics, hormonal function, and new approaches to therapy. Adv Pediatr. 2016;63(1):47-77.

52. Beauloye V, Diene G, Kuppens R, et al. High unacylated ghrelin levels support the concept of anorexia in infants with Prader-Willi syndrome. Orphanet J Rare Dis. 2016;11(1):56.

53. Hedgeman E, Ulrichsen SP, Carter S, et al. Long-term health outcomes in patients with Prader-Willi syndrome: a nationwide cohort study in Denmark. Int J Obes (Lond). 2017;41(10):1531-1538.

54. Stevenson DA, Heinemann J, Angulo M, et al. Deaths due to choking in Prader-Willi syndrome. Am J Med Genet A. 2007;143(5):484-487.

55. Stevenson DA, Heinemann J, Angulo M, et al. Gastric rupture and necrosis in Prader-Willi syndrome. J Pediatr Gastroenterol Nutr. 2007;45(2):272-274.

56. Einfeld SL, Kavanagh SJ, Smith A, Evans EJ, Tonge BJ, Taffe J. Mortality in Prader-Willi syndrome. Am J Ment Retard. 2006;111(3):193.

57. Butler MG, Manzardo AM, Heinemann J, Loker C, Loker J. Causes of death in Prader-Willi syndrome: Prader-Willi Syndrome Association (USA) 40-year mortality survey. Genet Med. 2017;19(6): $635-642$.

58. Laurier V, Lapeyrade A, Copet P, et al. Medical, psychological and social features in a large cohort of adults with Prader-Willi syndrome: experience from a dedicated centre in France. J Intellect Disabil Res. 2015;59(5):411-421.

59. Fintini D, Grugni G, Bocchini S, et al; Genetic Obesity Study Group of the Italian Society of Pediatric Endocrinology and Diabetology (ISPED). Disorders of glucose metabolism in Prader-Willi syndrome: results of a multicenter Italian cohort study. Nutr Metab Cardiovasc Dis. 2016;26(9):842-847.

60. Grugni G, Crinò A, Bedogni G, et al. Metabolic syndrome in adult patients with Prader-Willi syndrome. Nutr Metab Cardiovasc Dis. 2013;23(11):1134-1140.

61. Miller JL. Approach to the child with Prader-Willi syndrome. J Clin Endocrinol Metab. 2012;97(11):3837-3844.

62. Cataletto M, Angulo M, Hertz G, Whitman B. Prader-Willi syndrome: a primer for clinicians. Int J Pediatr Endocrinol. 2011;2011(1):12. 
63. McCandless SE; Committee on Genetics. Clinical report - health supervision for children with Prader-Willi syndrome. Pediatrics. 2011;127(1):195-204.

64. Alsaif M, Elliot SA, Mackenzie ML, Prado CM, Field CJ, Haqq AM. Energy metabolism profile in individuals with Prader-Willi syndrome and implications for clinical management: a systematic review. $A d v$ Nutr. 2017;8(6):905-915.

65. Bonfig W, Dokoupil K, Schmidt H. A special, strict, fat-reduced, and carbohydrate-modified diet leads to marked weight reduction even in overweight adolescents with Prader-Willi syndrome (PWS). Sci World J. 2009;9:934-939.

66. Barel G, Balko K, Viardot A. Nutritional issues and their management in PWS. In: Hoybye C, editor. Prader-Willi Syndrome. New York: Nova Science Publishers. 2013:137-156.

67. Lima VP, Emerich DR, Mesquita ML, et al. Nutritional intervention with hypocaloric diet for weight control in children and adolescents with Prader-Willi Syndrome. Eat Behav. 2016;21(4):189-192.

68. Miller JL, Lynn CH, Shuster J, Driscoll DJ. A reduced energy intake, well-balanced diet improves weight control in children with PraderWilli syndrome. J Hum Nutr Diet. 2013;26(1):2-9.

69. Butler MG, Hanchett JM, Thompson T. Clinical findings and natural history of Prader-Willi syndrome. In: Butler MG, Lee PDK, Whitman BY, editors. Management of Prader-Willi Syndrome. New York, USA: Springer; 2006:3-48.

70. Gourash L, Forster JL. Regulation of weight in Prader-Willi syndrome: theoretical and practical considerations; 2009. Available from: www. pittsburghpartnership.com.

71. Castner DM, Tucker JM, Wilson KS, Rubin DA. Patterns of habitual physical activity in youth with and without Prader-Willi syndrome. Res Dev Disabil. 2014;35(11):3081-3088.

72. Reus L, van Vlimmeren LA, Staal JB, Otten BJ, Nijhuis-van der Sanden MW. The effect of growth hormone treatment or physical training on motor performance in Prader-Willi syndrome: a systematic review. Neurosci Biobehav Rev. 2012;36(8):1817-1838.

73. Griggs JL, Sinnayah P, Mathai ML. Prader-Willi syndrome: from genetics to behaviour, with special focus on appetite treatments. Neurosci Biobehav Rev. 2015;59:155-172.

74. Salehi P, Leavitt A, Beck AE, Chen ML, Roth CL. Obesity management in Prader-Willi syndrome. Pediatr Endocrinol Rev. 2015;12(3):297-307.

75. Sahebkar A, Simental-Mendía LE, Reiner Ž, et al. Effect of orlistat on plasma lipids and body weight: a systematic review and meta-analysis of 33 randomized controlled trials. Pharmacol Res. 2017;122:53-65.

76. Butler MG. Management of obesity in Prader-Willi syndrome. Nat Clin Pract Endocrinol Metab. 2006;2(11):592-593.

77. Miller JL, Linville TD, Dykens EM. Effects of metformin in children and adolescents with Prader-Willi syndrome and earlyonset morbid obesity: a pilot study. J Pediatr Endocrinol Metab. 2014;27(1-2):23-29.

78. Hochberg I, Hochberg Z. Expanding the definition of hypothalamic obesity. Obes Rev. 2010;11(10):709-721.

79. Padwal RS, Majumdar SR. Drug treatments for obesity: orlistat, sibutramine, and rimonabant. Lancet. 2007;369(9555):71-77.

80. Kim GW, Lin JE, Blomain ES, Waldman SA. Antiobesity pharmacotherapy: new drugs and emerging targets. Clin Pharmacol Ther. 2014;95(1):53-66.

81. Fidler MC, Sanchez M, Raether B, et al. A one-year randomized trial of lorcaserin for weight loss in obese and overweight adults: the BLOSSOM trial. J Clin Endocrinol Metab. 2011;96(10):3067-3077.

82. Selikowitz M, Sunman J, Pendergast A, Wright S. Fenfluramine in Prader-Willi syndrome: a double blind, placebo controlled trial. Arch Dis Child. 1990;65(1):112-114.

83. Garfield AS, Davies JR, Burke LK, et al. Increased alternate splicing of Htr2c in a mouse model for Prader-Willi syndrome leads disruption of $5 \mathrm{HT}_{2 \mathrm{C}}$ receptor mediated appetite. Mol Brain. 2016;9(1):95.

84. Motaghedi R, Lipman EG, Hogg JE, Christos PJ, Vogiatzi MG, Angulo MA. Psychiatric adverse effects of rimonabant in adults with Prader Willi syndrome. Eur J Med Genet. 2011;54(1):14-18.
85. Billes SK, Sinnayah P, Cowley MA. Naltrexone/bupropion for obesity: an investigational combination pharmacotherapy for weight loss. Pharmacol Res. 2014;84:1-11.

86. Yanovski SZ, Yanovski JA. Naltrexone extended-release plus bupropion extended-release for treatment of obesity. JAMA. 2015;313(12):1213-1214.

87. Benjamin E, Buot-Smith T. Naltrexone and fluoxetine in Prader-Willi syndrome. J Am Acad Child Adolesc Psychiatry. 1993;32(4):870-873.

88. Zlotkin SH, Fettes IM, Stallings VA. The effects of naltrexone, an oral beta-endorphin antagonist, in children with the Prader-Willi syndrome. J Clin Endocrinol Metab. 1986;63(5):1229-1232.

89. Deal CL, Tony M, Hoybye C, et al. Growth Hormone Research Society workshop summary: consensus guidelines for recombinant human growth hormone therapy in Prader-Willi syndrome. J Clin Endocrinol Metab. 2013;98(6):E1072-E1087.

90. Carrel AL, Myers SE, Whitman BY, Eickhoff J, Allen DB. Long-term growth hormone therapy changes the natural history of body composition and motor function in children with Prader-Willi syndrome. J Clin Endocrinol Metab. 2010;95(3):1131-1136.

91. Höybye C. Growth hormone treatment of Prader-Willi syndrome has long-term, positive effects on body composition. Acta Paediatr. 2015;104(4):422-427

92. Myers SE, Whitman BY, Carrel AL, Moerchen V, Bekx MT, Allen DB. Two years of growth hormone therapy in young children with Prader-Willi syndrome: physical and neurodevelopmental benefits. Am J Med Genet A. 2007;143(5):443-448.

93. Sipilä I, Sintonen H, Hietanen H, et al. Long-term effects of growth hormone therapy on patients with Prader-Willi syndrome. Acta Paediatr. 2010;99(11):1712-1718.

94. Bakker NE, Kuppens RJ, Siemensma EP, et al. Eight years of growth hormone treatment in children with Prader-Willi syndrome: maintaining the positive effects. J Clin Endocrinol Metab. 2013;98(10):4013-4022.

95. Tan TM, Vanderpump M, Khoo B, Patterson M, Ghatei MA, Goldstone AP. Somatostatin infusion lowers plasma ghrelin without reducing appetite in adults with Prader-Willi syndrome. J Clin Endocrinol Metab. 2004;89(8):4162-4165.

96. de Waele K, Ishkanian SL, Bogarin R, et al. Long-acting octreotide treatment causes a sustained decrease in ghrelin concentrations but does not affect weight, behaviour and appetite in subjects with PraderWilli syndrome. Eur J Endocrinol. 2008;159(4):381-388.

97. Aman LCS, Manning KE, Whittington JE, Holland AJ. Mechanistic insights into the genetics of affective psychosis from Prader-Willi syndrome. Lancet Psychiatry. 2018;5(4):370-378.

98. Shapira NA, Lessig MC, Lewis MH, Goodman WK, Driscoll DJ. Effects of topiramate in adults with Prader-Willi syndrome. Am J Ment Retard. 2004;109(4):301-309.

99. Sze L, Purtell L, Jenkins A, et al. Effects of a single dose of exenatide on appetite, gut hormones, and glucose homeostasis in adults with PraderWilli syndrome. J Clin Endocrinol Metab. 2011;96(8):E1314-E1319.

100. Seetho IW, Jones G, Thomson GA, Fernando DJS. Treating diabetes mellitus in Prader-Willi syndrome with exenatide. Diabetes Res Clin Pract. 2011;92(1):e1-e2.

101. Arenz T, Schwarzer A, Pfluger T, Koletzko S, Schmidt H. Delayed gastric emptying in patients with Prader Willi syndrome. J Pediatr Endocrinol Metab. 2010;23(9):867-871.

102. Fintini D, Grugni G, Brufani C, Bocchini S, Cappa M, Crino A. Use of GLP-1 receptor agonists in Prader-Willi syndrome: report of six cases. Diabetes Care. 2014;37(4):e76-e77.

103. Miller JL, Strong TV, Heinemann J. Medical trials for hyperphagia and food-related behaviors in Prader-Willi syndrome. Diseases. 2015;3(2):78-85.

104. Kim DD, Krishnarajah J, Lillioja S, et al. Efficacy and safety of beloranib for weight loss in obese adults: a randomized controlled trial. Diabetes Obes Metab. 2015;17(6):566-572.

105. Mccandless SE, Yanovski JA, Miller J, et al. Effects of MetAP2 inhibition on hyperphagia and body weight in Prader-Willi syndrome: a randomized, double-blind, placebo-controlled trial. Diabetes Obes Metab. 2017;19(12):1751-1761. 
106. Burkey BF, Hoglen NC, Inskeep P, Wyman M, Hughes TE, Vath JE. Preclinical efficacy and safety of the novel antidiabetic, antiobesity MetAP2 inhibitor ZGN-1061. J Pharmacol Exp Ther. 2018;365(2):301-313.

107. Bischof JM, van der Ploeg LH, Colmers WF, Wevrick R. Magel2-null mice are hyper-responsive to setmelanotide, a melanocortin 4 receptor agonist. Br J Pharmacol. 2016;173(17):2614-2621.

108. Bischof JM, Wevrick R. Chronic diazoxide treatment decreases fat mass and improves endurance capacity in an obese mouse model of Prader-Willi syndrome. Mol Genet Metab. 2018;123(4):511-517.

109. Kimonis V, Gold JA, Surampalli A, Wencel M. Efficacy and safety of diazoxide choline controlled-release tablet in patients with Prader-Willi syndrome: an updated analysis. Horm Res Paediatr. 2017;88(suppl 1):211;P1-1611.

110. Einfeld SL, Smith E, Mcgregor IS, et al. A double-blind randomized controlled trial of oxytocin nasal spray in Prader Willi syndrome. Am J Med Genet A. 2014;164(9):2232-2239.

111. Kuppens RJ, Donze SH, Hokken-Koelega AC. Promising effects of oxytocin on social and food-related behaviour in young children with Prader-Willi syndrome: a randomized, double-blind, controlled crossover trial. Clin Endocrinol (Oxf). 2016;85(6):979-987.

112. Miller JL, Tamura R, Butler MG, et al. Oxytocin treatment in children with Prader-Willi syndrome: a double-blind, placebo-controlled, crossover study. Am J Med Genet A. 2017;173(5):1243-1250.

113. Tauber M, Boulanouar K, Diene G, et al. The use of oxytocin to improve feeding and social skills in infants with Prader-Willi syndrome. Pediatrics. 2017;139(2):e20162976.

114. Rice LJ, Einfeld SL, Hu N, Carter CS. A review of clinical trials of oxytocin in Prader-Willi syndrome. Curr Opin Psychiatry. 2018;31(2):123-127.

115. Dykens EM, Miller J, Angulo M, et al. Intranasal carbetocin reduces hyperphagia in individuals with Prader-Willi syndrome. JCI Insight. 2018;3(12):98333.

116. Allas S, Caixas A, Poitou C, et al. AZP-531, an unacylated ghrelin analog, improves food-related behavior in patients with PraderWilli syndrome: a randomized placebo-controlled trial. PLoS One. 2018;13(1):e0190849.

117. Griggs JL, Su XQ, Mathai ML. Caralluma fimbriata supplementation improves the appetite behavior of children and adolescents with Prader-Willi syndrome. Am J Med Sci. 2015;7(11):509-516.

118. Ho AL, Sussman ES, Pendharkar AV, Azagury DE, Bohon C, Halpern $\mathrm{CH}$. Deep brain stimulation for obesity: rationale and approach to trial design. Neurosurg Focus. 2015;38(6):E8.

119. Bravo GL, Poje AB, Perissinotti I, et al. Transcranial direct current stimulation reduces food-craving and measures of hyperphagia behavior in participants with Prader-Willi syndrome. Am J Med Genet B Neuropsychiatr Genet. 2016;171B(2):266-275.

120. Peterli R, Wölnerhanssen BK, Peters T, et al. Effect of laparoscopic sleeve gastrectomy vs laparoscopic Roux-en-Y gastric bypass on weight loss in patients with morbid obesity: the SM-BOSS randomized clinical trial. JAMA. 2018;319(3):255-265.
121. Iossa A, De Peppo F, Caccamo R, et al. Laparoscopic sleeve gastrectomy in adolescents with or without syndromic obesity: two years follow-up. Eat Weight Disord. 2018;23(4):479-486.

122. Nobili V, Vajro P, Dezsofi A, et al. Indications and limitations of bariatric intervention in severely obese children and adolescents with and without nonalcoholic steatohepatitis: ESPGHAN Hepatology Committee Position Statement. J Pediatr Gastroenterol Nutr. 2015;60(4):550-561

123. Shoar S, Mahmoudzadeh H, Naderan M, et al. Long-term outcome of bariatric surgery in morbidly obese adolescents: a systematic review and meta-analysis of 950 patients with a minimum of 3 years followup. Obes Surg. 2017;27(12):3110-3117.

124. Khidir N, El-Matbouly MA, Sargsyan D, et al. Five-year outcomes of laparoscopic sleeve gastrectomy: a comparison between adults and adolescents. Obes Surg. 2018;28(7):2040-2045.

125. Alqahtani AR, Elahmedi MO, Al Qahtani AR, Lee J, Butler MG. Laparoscopic gastrectomy in children and adolescents with PraderWilli syndrome: a matched-control study. Surg Obes Relat Dis. 2016;12(1):100-110

126. Cazzo E, Gestic MA, Utrini MP, et al. Bariatric surgery in individuals with severe cognitive impairment: report of two cases. Sao Paulo Med J. 2018;136(1):84-88.

127. Gibbons E, Casey AF, Brewster KZ. Bariatric surgery and intellectual disability: furthering evidence-based practice. Disabil Health J. 2017;10(1):3-10.

128. Michalik M, Frask A, Lech P, Zdrojewski M, Doboszynska A. The usefulness of biliopancreatic diversion/Scopinaro operation in treatment of patients with Prader-Willi syndrome. Wideochir Inne Tech Maloinwazyjne. 2015;10(2):324-327.

129. Musella M, Milone M, Leongito M, Maietta P, Bianco P, Pisapia A. The mini-gastric bypass in the management of morbid obesity in PraderWilli syndrome: a viable option? J Invest Surg. 2014;27(2):102-105.

130. Fong AK, Wong SK, Lam CC, Ng EK. Ghrelin level and weight loss after laparoscopic sleeve gastrectomy and gastric mini-bypass for PraderWilli syndrome in Chinese. Obes Surg. 2012;22(11):1742-1745.

131. Scheimann AO, Butler MG, Gourash L, Cuffari C, Klish W. Critical analysis of bariatric procedures in Prader-Willi syndrome. J Pediatr Gastroenterol Nutr. 2008;46(1):80-83.

132. Busetto L, Dicker D, Azran C, et al. Obesity Management Task Force of the European Association for the Study of Obesity released "practical recommendations for the post-bariatric surgery medical management". Obes Surg. 2018;28(7):2117-2121.

133. Moura D, Oliveira J, de Moura EG, et al. Effectiveness of intragastric balloon for obesity: a systematic review and meta-analysis based on randomized control trials. Surg Obes Relat Dis. 2016;12(2):420-429.

134. De Peppo F, Di Giorgio G, Germani M, et al. BioEnterics intragastric balloon for treatment of morbid obesity in Prader-Willi syndrome. Obes Surg. 2008;18(11):1443-1449.

135. Alqahtani AR, Elahmedi M, Alqahtani YA. Bariatric surgery in monogenic and syndromic forms of obesity. Semin Pediatr Surg. 2014;23(1):37-42.

Diabetes, Metabolic Syndrome and Obesity: Targets and Therapy

\section{Publish your work in this journal}

Diabetes, Metabolic Syndrome and Obesity: Targets and Therapy is an international, peer-reviewed open-access journal committed to the rapid publication of the latest laboratory and clinical findings in the fields of diabetes, metabolic syndrome and obesity research Original research, review, case reports, hypothesis formation, expert opinion and commentaries are all considered for publication. The manuscript management system is completely online and includes a very quick and fair peer-review system, which is all easy to use. Visit http://www.dovepress.com/testimonials.php to read real quotes from published authors. 